\title{
Characterization of Environmental Nano- and Macrocolloid Particles Extracted from Selected Soils and Biosolids
}

\author{
J. L. Ghezzi, A. D. Karathanasis, C. J. Matocha, J. Unrine, and Y. L. Thompson \\ Department of Plant and Soil Sciences, University of Kentucky, Lexington, KY 40546, USA \\ Correspondence should be addressed to A. D. Karathanasis; akaratha@uky.edu
}

Received 10 February 2014; Revised 17 March 2014; Accepted 18 March 2014; Published 14 April 2014

Academic Editor: Rafael Clemente

Copyright (C) 2014 J. L. Ghezzi et al. This is an open access article distributed under the Creative Commons Attribution License, which permits unrestricted use, distribution, and reproduction in any medium, provided the original work is properly cited.

\begin{abstract}
Environmental nanoparticles found in soil systems and biosolids may pose a considerable risk to groundwater quality as contaminant carriers. Little effort has been invested in the characterization of natural nanocolloids compared to corresponding macrocolloids. This study involved physicochemical, mineralogical, and morphological characterizations of nanocolloids and macrocolloids fractionated from three Kentucky soils and one biosolid. Particle size and morphology were investigated using scanning/transmission electron microscopy and dynamic light scattering. Mineralogical composition was determined by X-ray diffraction and thermogravimetric and Fourier-transform infrared spectroscopy analyses. Zeta potentials and cation exchange capacities assessed surface charge and chemical reactivity. The estimated average hydrodynamic diameter of nanoparticles was nearly twice the ideal $100 \mathrm{~nm}$ range, apparently due to irregular particle shapes and partial aggregation. Nanoparticles were also found attached to surfaces of macrocolloids, forming macro-nano aggregates and obscuring some of their physical and chemical characteristics. However, nanocolloids exhibited greater surface reactivity, likely due to their smaller size, poor crystallinity, and morphological shape distortions. In spite of some behavior modification due to nanoaggregation phenomena, nanocolloids appeared to be much more potent vectors of contaminant transport in subsurface environments than their macrosize fractions. Nevertheless, their heterogeneous nature brings to light important considerations in addressing pollution prevention and remediation challenges.
\end{abstract}

\section{Introduction}

It has long been accepted that soil acts as a filtration medium between contaminants at the surface of the geosphere and groundwater. However, despite the role of the soil as a "filter," a large portion of contaminants still reach groundwater supplies. The transport of contaminants to groundwater aquifers is a function of multiple processes, some of which include soluble phases, microorganisms, or sorption onto environmental colloids [1-3]. The IUPAC defines colloids as dispersed media with average diameters of $1-1,000 \mathrm{~nm}$ [4]. This definition includes nanoparticles, which by definition are particles with "at least one dimension equal to or less than $100 \mathrm{~nm}$ " [1, 4-7]. Although the properties and behavior of environmental colloids have been studied extensively, very little information exists on natural environmental nanocolloids and their differences from their corresponding larger macrocolloid fractions.

What differentiates nanoparticles (or nanocolloids) from their larger scale counterparts is that, in addition to and as a function of their smaller size, their mechanical, structural, and chemical characteristics change, making them drastically different from their corresponding macroparticles (or macrocolloids) [6-9]. In natural systems, soil nanocolloids may include inorganic and organic nanoparticles such as clay minerals and colloids, metal hydroxides, and humic substances $[2,7,10]$. Biosolid nanocolloids come from anthropogenic or animal-derived wastes which are introduced into the environment through land application as fertilizers [11]. Soil and biosolid nanocolloids are active in many environmental processes, including but not limited to soil genesis, dispersion/flocculation, nutrient cycling, bioavailability, contaminant transport, and various remediation processes $[1,2]$.

Due to their smaller size there are likely differences in nanoparticle (nanocolloid) physicochemical, morphological, and mineralogical characteristics as compared to their corresponding macroparticles (macrocolloids). The changes in characteristics between nanoparticles (nanocolloids) and their corresponding larger fractions (macrocolloids) may include substantial differences in molecular and electronic 
structure, mechanical behavior, and chemical reactivity, with the greatest changes occurring at particle sizes of $10 \mathrm{~nm}$ or less [9]. It is at these smaller sizes that changes in surface bonding, shape, and energy considerations affect strain, reactivity, phase transformations, and structure of the particles [9]. Because of their smaller size, nanocolloids are expected to have larger surface areas and, depending on their mineralogy and organic content, higher surface charge and sorption capacities as compared to macrocolloids. This insinuates that nanocolloids may be a greater threat to groundwater quality due to their greater contaminant loading potential as compared to macrocolloids $[1,2]$.

On a morphological basis, nanoparticles are typically shaped differently than their larger counterparts due to the size limitation in at least one dimension, resulting in nanosheets, -rods, or other particle shapes and surface constraints $[5,6,8]$. Mineralogically, previous studies performed on soil clays of $200-80 \mathrm{~nm}$ in size have indicated size based composition trends, including decreased amounts of mica or hydroxyl-interlayered vermiculite and increased amounts of kaolinite and gibbsite as compared to larger size fractions [12-15]. It is reasonable, then, to expect nanoparticles or "nanocolloids" to show size separation trends (i.e., hydroxylinterlayer vermiculite, mica versus kaolinitic, and gibbsite) as well as to contain more weatherable minerals and lower $\mathrm{Si}$ : Al ratios (excluding smectite) than their larger scale counterparts [12, 13, 16-18]. Studies have also shown that soil colloids with higher $\mathrm{Al}$ or Fe content than Si have greater potential to sorb humic acids to their surfaces and will display greater reactivity, stability, and mobility potentials [18]. Higher quantities of amorphous phases found in the fine-clay fraction $(<200 \mathrm{~nm})$ may also contribute to higher chemical reactivity and sorption capacities to nanocolloids over that of their larger sized counterparts $[12,13]$. The combination of surface constraints, particle morphology, and enhanced chemical reactivity based on mineralogy may drastically alter nanocolloid sorption characteristics as compared to that of their larger size macrocolloid particles.

Since soil colloids have been shown to carry contaminants, they are of particular interest in environmental pollution, water quality, and remediation processes $[19,20]$. In the past, environmental colloid research focused on their physicochemical, mineralogical, and morphological characterization, as well as their mobility and contaminant transport potential. While it has been well documented that natural colloids derived from soil and biosolid systems are capable of transporting contaminants into surface and ground waters $[15,19-22]$, currently, very little information exists that distinguishes the characteristics and behavior of nano- and macrocolloid sized particles in natural environments. It is anticipated that nanocolloids may have drastically different physical, chemical, morphological, and mineralogical characteristics than macrocolloids: (i) physically, nanocolloids are likely to have larger and more reactive surface areas than macrocolloids, (ii) chemically, nanocolloids may have greater chemical reactivity, as evidenced by greater surface charges and exchange capacities than macrocolloids, (iii) morphologically and mineralogically, nanocolloids could contain more amorphous materials and highly weathered minerals than macrocolloids. Therefore, nanocolloids may have a greater potential than macrocolloids to negatively impact groundwater supplies. The objectives of this study were to evaluate and compare differences in physicochemical, morphological, and mineralogical characteristics of nanoand macrocolloid fractions separated from three soils with diverse mineralogy and one anaerobically digested biosolid waste material.

\section{Materials and Methods}

2.1. Colloid Generation. Mineral colloids were generated from Bt horizons of three Kentucky soils of differing mineralogy: Caleast-variant (fine, smectitic, mesic mollic Hapludalf), Tilsit (fine-silty, mixed, mesic Typic Fragiudult), and Trimble (fine-loamy, siliceous, mesic Typic Paleudult), which will be referred to as smectitic, mixed, and kaolinitic, respectively. An aerobically digested municipal sewage sludge was obtained from Jessamine County, Kentucky, and utilized to fractionate the biosolid colloids. To fractionate, 15 grams of moist bulk soil/biosolid sample was mixed with $200 \mathrm{~mL}$ of deionized water (resistivity of $1 \mu \Omega \mathrm{cm}$ at $25^{\circ} \mathrm{C}$ ) in plastic bottles (without addition of dispersing agent), shaken overnight, followed by 5 minutes of ultrasonification, and then centrifuged. Colloids were fractionated using centrifugation into two size classes (nanocolloids $<100 \mathrm{~nm}$ and macrocolloids 100-2000 nm) using a Centra GP8R Model 120 centrifuge (ThermoIEC). Centrifugation was performed at $107 \mathrm{RCF}$ for 3.5 minutes to separate the clay fraction from the bulk soil, and then the nanocolloids were separated from the macrocolloids via centrifugation at $4387 \mathrm{RCF}$ for 46 minutes $[2,23]$. Stokes law was used to determine centrifugation times with a rotor radius of $170 \mathrm{~mm}$, a speed of $4387 \mathrm{RCF}$, a density difference from water of $1650 \mathrm{~kg} \mathrm{~m}^{-3}$, and viscosity of 0.0008904 Pas, while the separation of the clay fraction from the bulk soil was calculated using a rotor radius of $170 \mathrm{~mm}$, using $107 \mathrm{RCF}$, a density difference of $1650 \mathrm{~kg} \mathrm{~m}^{-3}$, and viscosity of 0.0008904 Pas.

2.2. Particle Size, Morphology, and Surface Area Analysis. A Malvern Instruments Zetasizer Nano ZS (Malvern, United Kingdom) was used to determine intensity weighted mean particle hydrodynamic diameters ( $z$-average diameter) of triplicate sample suspensions with concentrations of $50 \mathrm{mg}$ colloid $\mathrm{L}^{-1}$ using dynamic light scattering $\left(173^{\circ}\right.$ backscatter analysis method). Primary particle size of nanocolloid crystallites was determined using high resolution transmission electron microscopy (Jeol 2010F, Tokyo, Japan). TEM-EDS grids were prepared with nanocolloids after vortexing $40 \mathrm{~mL}$ of $50 \mathrm{mg}$ colloid $\mathrm{L}^{-1}$ deionized water suspensions, spreading $1 \mathrm{~mL}$ aliquots out on parafilm-backing paper, and then swabbing a 400 mesh Cu grid (number 01824 Ted Pella, Redding, CA, USA) through the suspension. Images were collected using a JEOL 2010F electron microscope with an ultrahigh resolution pole piece operating at $200 \mathrm{keV}$ with a field emission gun attached to an Oxford EDS detector $[24,25]$. Primary particle size of macrocolloid crystallites was determined using scanning electron microscopy (SEM; 
Hitachi S-4300, Tokyo, Japan) [24, 25]. SEM-EDS stubs were prepared with macrocolloids after vortexing $40 \mathrm{~mL}$ of 2,500 $\mathrm{mg}$ colloid $\mathrm{L}^{-1}$ deionized water suspensions, spreading $1 \mathrm{~mL}$ aliquots onto parafilm paper, and then swabbing the carbon tape through the suspension. The carbon tape was then attached to an $\mathrm{Al}$ holder and sputter coated with $\mathrm{Au} / \mathrm{Pd}$. Images were collected on a Hitachi S-4300 scanning electron microscope equipped with a Princeton Gamma-Tech EDS Microanalysis system [26, 27]. All samples were dried in a laminar flow hood for 48 hours prior to TEM- or SEM-EDS analysis. The average diameters were calculated using ImageJ software to measure the minimum diameter of 300 representative particles (until the mean and standard deviation stabilized) from three to eight separate representative images of each colloid (ImageJ 1.46r, Wayne Rasband, National Institutes of Health, USA). The morphology of nano- and macrocolloid fractions was evaluated using HRTEM-EDS and SEM-EDS, respectively. Surface area analysis was performed in triplicates on both the nano- and macrocolloids using the ethylene glycol monoethyl ether (EGME) method [28].

2.3. Chemical Characterization. Colloid suspension concentrations were determined by oven drying triplicate samples at $100^{\circ} \mathrm{C}$ for 24 hours. Concentrations allowed for determination of water dispersible colloid (WDC) percentages for each size fraction prior to diluting all suspensions to $50 \mathrm{mg} \mathrm{L}^{-1}$ concentrations for further analyses. The electrical conductivity and $\mathrm{pH}$ of the nano- and macrocolloid suspensions was determined using a Denver Instruments Model $250 \mathrm{pH}^{*}$ ISE$^{*}$ electrical conductivity meter (Arvada, CO). Electrical conductivities were multiplied by 0.0127 to estimate ionic strength [29]. Triplicate samples of the nano- and macrocolloids were analyzed for cation exchange capacity (CEC) using an adapted version of the ammonium acetate method (where ratios of reagents were adapted to reflect the $50 \mathrm{mg} \mathrm{L}^{-1}$ colloid concentrations) and reported as a sum of the base cations $\mathrm{Ca}^{2+}, \mathrm{Mg}^{2+}, \mathrm{K}^{+}$, and $\mathrm{Na}^{+}$. The base cation concentrations were analyzed with a Varian Spectra AA 50B atomic absorption spectrometer [30]. Organic Carbon was derived by subtracting dissolved organic carbon from total carbon as measured on a Flash EA 1112 Series NC Soil Analyzer (Thermo Electron Corporation) with a Mettler Toledo MX5 microbalance. Due to low $\mathrm{pH}$ conditions and the typical absence of carbonates in the region, inorganic carbon contributions were assumed to be minimal. Surface and point of zero charge (PZC) analyses were accomplished by converting electrophoretic mobility measurements taken on a Malvern Zetasizer Nano ZS to zeta potentials using the Smoluchowski approximation. Zeta potentials were measured on suspensions with a $0.001 \mathrm{M} \mathrm{NaCl}$ background electrolyte where $\mathrm{pH}$ was adjusted to $4,6,8$, and 10 using $0.01 \mathrm{~N} \mathrm{NaOH}$ and $\mathrm{HCl}$ (Malvern, United Kingdom).

2.4. Mineralogical Characterization. A combination of $\mathrm{X}$ ray diffraction (XRD), thermogravimetric analysis (TG), and Diffuse reflectance infrared Fourier-transform (DRIFT) spectroscopy was used for mineralogical characterization. For XRD analysis, $\mathrm{K}, \mathrm{Mg}$, and $\mathrm{Mg}$-glycerol saturated samples were collected on glass slides and analyzed on a Philips PW
1840 diffractometer and PW 1729 X-ray generator (Mahwah, NJ) fitted with a cobalt X-ray tube and run at $40 \mathrm{kV}$ and $30 \mathrm{~mA}$ using a Bragg-Bretano design goniometer at a scanning rate of $0.05^{\circ} 2 \theta$ per minute from $2^{\circ}$ to $40^{\circ}$ with a scattering slit of $0.1^{\circ}$. Philips Automated Powder Diffraction software (version 3.5B) was used to analyze the obtained XRD patterns (Mahwah, NJ). K-saturated slides underwent heat treatments to verify the presence of kaolinite as well as to differentiate hydroxy-interlayered minerals from smectite and vermiculite. Mg-saturated colloids were also used for TG analysis on a Thermal Analyst 2000 (TA Instruments) equipped with a 951 Thermogravimetric Analyzer (DuPont Instruments) with a heating rate of $20^{\circ} \mathrm{C} / \mathrm{min}$ under $\mathrm{N}_{2}$ atmosphere [23, 31]. TG analysis was performed using the General DuPont 2000 software program (version 4.1C, DuPont Instruments). The TG analysis was used to verify the presence of kaolinite as well as goethite and gibbsite and to compliment quantification interpretations derived from the XRD patterns [23, 31]. DRIFT spectroscopy was used for mineralogical characterization of the macro- and nanocolloids and their complexes with soil organic matter [26, 32-34]. DRIFT spectroscopy was performed on a Nicolet 6700 FT-IR Model spectrometer with a Thermo Fisher Smart Collector Diffuse Reflectance accessory, using a 600$4000 \mathrm{~cm}^{-1}$ reciprocal range obtained at 4 reciprocal cm${ }^{-1}$ resolution, with the coaddition of 200 scans using a liquid $\mathrm{N}_{2}$ cooled MCT detector. The DRIFT samples were prepared by homogenizing oven-dried colloids combined with spectroscopic grade $\mathrm{KBr}$ at a $5 \%$ ratio and then poured into a sample cup of about $1 \mathrm{~mm}$ depth and $3 \mathrm{~mm}$ diameter to obtain random orientation. The OMNIC32 software (Thermo Electron Corporation, Madison, WI) was used to analyze spectra obtained from the nano- and macrocolloids.

2.5. Statistical Analysis. The accepted error levels for all duplicate and triplicate measurements were $\leq 15 \%$. Significant differences between means were tested using analysis of variance (ANOVA) (SAS PROC GLM) and Fisher's protected least significant difference test (LSD) in SAS 9.3 (SAS Institute Inc., Cary, NC, USA). The statistical significance level used was $\alpha=0.05$.

\section{Results and Discussion}

3.1. Particle Size and Surface Area Analysis. The average intensity weighted ( $Z$-average) hydrodynamic diameter $\left(d_{h}\right)$ of nanocolloid particles measured by DLS was nearly double the ideal maximum size of $100 \mathrm{~nm}$ for the mineral fractions (regardless of mineralogy) and 3.5 times greater for the biosolid fractions (Table 1). This may suggest incomplete separation of nanosized particles but it may also reflect on the diversity of the shape of the particles. Environmental nanoparticles are seldom spherical and occur in a variety of shapes [5]. Considering that nanoparticles by definition have a size range of $<100 \mathrm{~nm}$ in at least one dimension, they may have sizes $>100 \mathrm{~nm}$ in other dimensions. Since the DLS measures the intensity weighted average, the calculated hydrodynamic diameter represents the average size of the particles. This explanation was supported by TEM analysis 


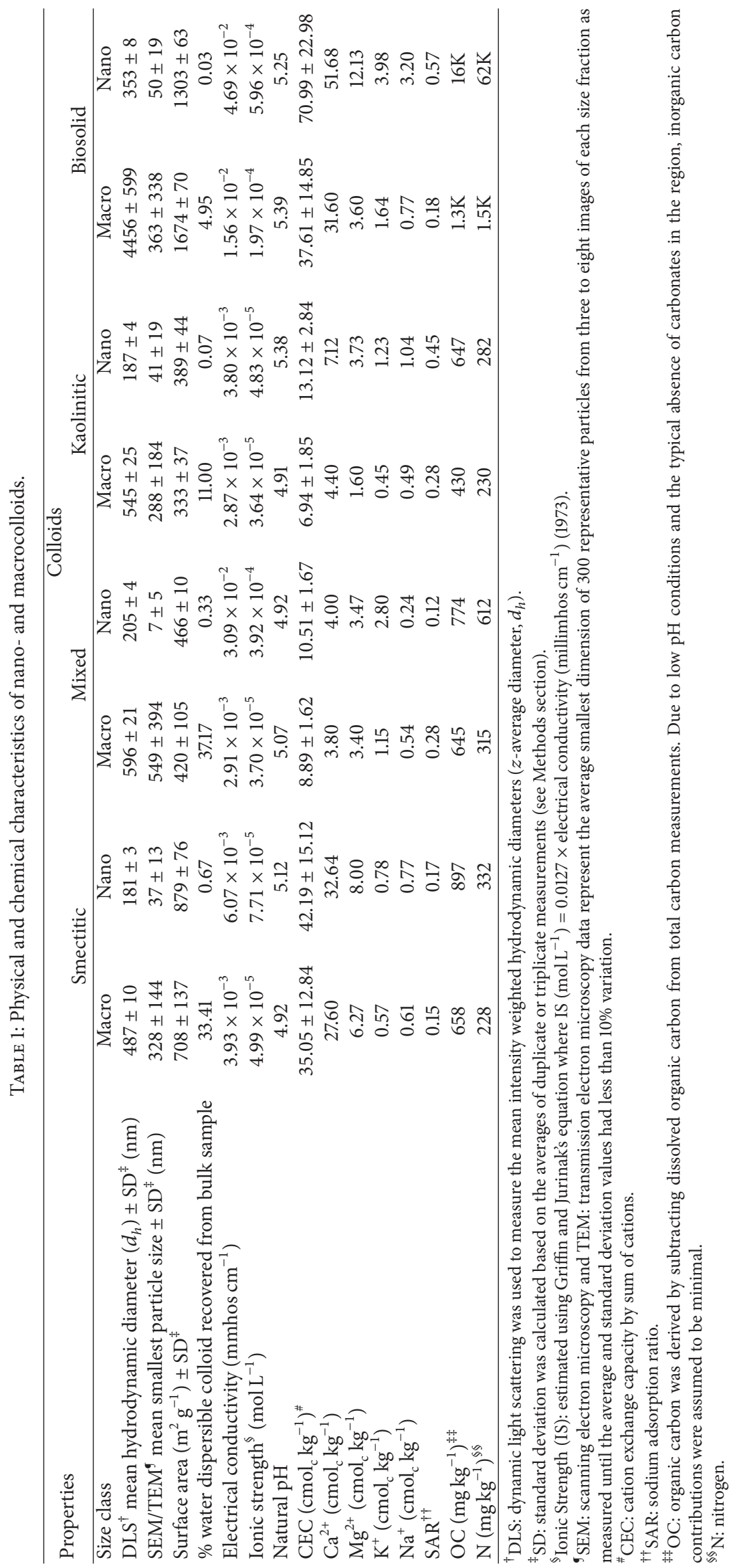


indicating the majority of individual nanoparticles to be in the $<100 \mathrm{~nm}$ size range. This does not preclude some limited aggregation that may have occurred after centrifugation, particularly with the biosolid fraction. Even a small mass of aggregates in this case may have large effects on the intensity weighted $d_{h}$ because it is heavily weighed towards the larger size particles [14, 21]. Dynamic light scattering analysis of macrocolloid mineral particles indicated $Z$-average $d_{h}$ between 487 and $596 \mathrm{~nm}$, with the smaller size representing smectitic mineralogy (Table 1). Biosolid macrocolloid particles averaged larger $d_{h}$ than the mineral counterparts, potentially reflecting aggregation through organic ligand interactions (Table 1).

A significant finding of the SEM/TEM analysis was that a considerable number of macrocolloid particles had nanoparticles adhered onto their surfaces (Figure 1). This observation may insinuate that the initial separation of nanoand macrocolloid fractions via centrifugation without a dispersive agent may have been inadequate for lack of effective dispersion. SEM/TEM images showed a variety of platy or rod-like images suggesting that the spherical particle shape assumption used by Stokes law would obviously obscure size separation via centrifugation (Figures 1 and 2). The use of a dispersing agent to induce further dispersion was purposely avoided in order to better represent natural conditions and eliminate artifacts. The adhesion of nanoparticles onto colloid surfaces may have also obscured the mineralogical composition of macrocolloid fractions due to segregation phenomena and enhanced their surface reactivity and sorption capacity (Table 1). Particle size analysis by TEM indicated the majority of nanoparticles to have a smaller size range dimension of 7 to $50 \mathrm{~nm}$, while SEM of the macrocolloid fractions showed a range between 288 and $549 \mathrm{~nm}$ (Table 1, Figure 2). These observations confirm that the centrifugation based primary particle size estimates may have been somewhat misleading even though some aggregation impacts may not be discounted.

In spite of the adhesion of some nanoparticles onto macrocolloid surfaces, the mineral nanocolloids exhibited overall greater surface area than the macrocolloids (Table 1). The surface areas measured varied amongst colloid types, with the largest values associated with the biosolid, followed by the smectitic, mixed, and kaolinitic colloids (Table 1). The large surface area of the biosolid colloids is apparently associated more with the extent of organic functional groups and acids associated with their composition rather than their size. Smectitic mineralogies typically have greater surface availability than kaolinitic or mixed mineralogies due to the larger percentage of expanding 2:1 minerals present [35].

3.2. Morphological Characteristics. The morphology of the smectitic macrocolloids was typical of montmorillonite, showing a honeycomb-like appearance with edge-face interactions in the SEM images (Figure 1(a)). The TEM-EDS data from the smectitic nanocolloids also showed an increase in iron minerals (Figure 2(a)) as opposed to their larger macrocolloid counterparts [25]. The mixed mineralogy macrocolloids also showed some aggregated honeycomb morphology but mostly granulated platy clusters in SEM images
(Figure 1(b)). The TEM images of the mixed mineralogy nanocolloids showed multiple particle shapes ranging from tubes/rods to plates and hexagons, suggesting increased shape deformation with decreasing size (Figure 2(b)). Similar images were shown by Németh et al. [24] for HIV with associated iron minerals. The SEM images of the kaolinitic macrocolloids showed the typical hexagonal shapes displayed by kaolinitic minerals (Figure 1(c)). Kaolinitic nanocolloid TEM images involved much smaller hexagonal shapes with noted increases in iron minerals embedded within and binding the hexagonal aggregates (Figure 1(c)) [25]. SEM images of biosolid macrocolloids included mainly aggregated organic material in various forms coating the surfaces of quartz grains (Figure 1(d)), while TEM images of the biosolid nanocolloids showed aggregated organic material, with much more dissolution of particle shape and less sample integrity (Figure 2(d)). Overall, the macrocolloids appeared to have better crystallinity and shape integrity thanthe nanocolloids. Similar findings were reported by Zhu and $\mathrm{Lu}$ [25], who also found increases of iron minerals in nanoparticles as opposed to larger size mineral classes. The TEM images in this study also showed nanocolloid structures with increased interlayering and disorder in their structures and embedded iron minerals (Figure 3) [25] that may cause greater shape and surface constraints in the nanocolloids as compared to the macrocolloids [6].

\subsection{Chemical Characteristics}

3.3.1. Characteristics of Water Dispersible Colloids. The percentage of water dispersible colloids (WDC) recovered from the bulk Bt horizon samples indicated greater quantities of macro-WDC than nano-WDC in all three soil types (Table 1). This agrees with Kjaergaard et al. [14, 15], who fractionated two size classes of WDC, $<0.2 \mu \mathrm{m}$ and $0.2-$ $2.0 \mu \mathrm{m}$, and recovered greater amounts of WDC in the latter. The mixed and smectitic colloids produced greater amounts of WDC when compared with kaolinitic colloids (Table 1). This indicates the important role of clay mineralogy in dictating WDC content. Past studies have noted that soils with increasing amounts of kaolinite are less prone to disperse [36]. The WDC percentages may be useful for predicting the amount of potentially mobile colloids in a soil profile.

The original $\mathrm{pH}$ of soil colloids is also an important factor in dictating WDC content, with acidic conditions promoting flocculation [37]. The unadjusted $\mathrm{pH}$ of the nanocolloids had a range of 4.92 to 5.38 (mixed and kaolinitic colloids, resp.) and the macrocolloids had a $\mathrm{pH}$ range of 4.91 to 5.39 (kaolinitic and biosolid colloids, resp.) (Table 1). This relatively narrow range suggests that original $\mathrm{pH}$ values did not strongly influence WDC content in the three soil types.

Despite low overall electrical conductivity (EC) and ionic strength (IS) values (all values below $5 \times 10^{-3} \mathrm{mmhos} \mathrm{cm}^{-1}$ and $6 \times 10^{-4} \mathrm{~mol} \mathrm{~L}^{-1}$, resp.), the EC and IS values for the nanocolloids were higher than those of their corresponding macrocolloids, with the biosolid colloids showing greater EC and IS suspensions than the mineral colloids (Table 1). The higher ionic strengths for each of nanocolloids might have contributed to the lower amounts of WDC recovered when 


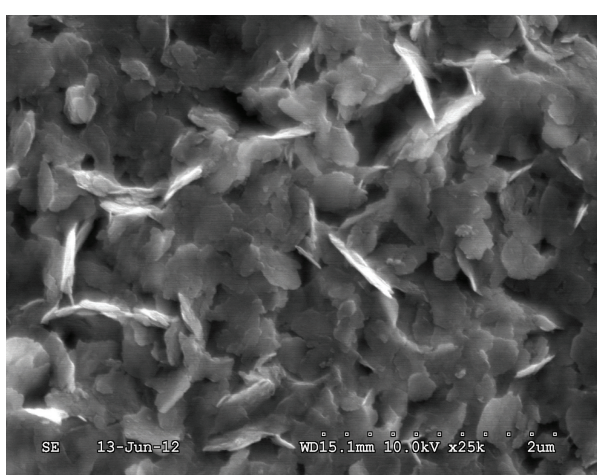

(a)

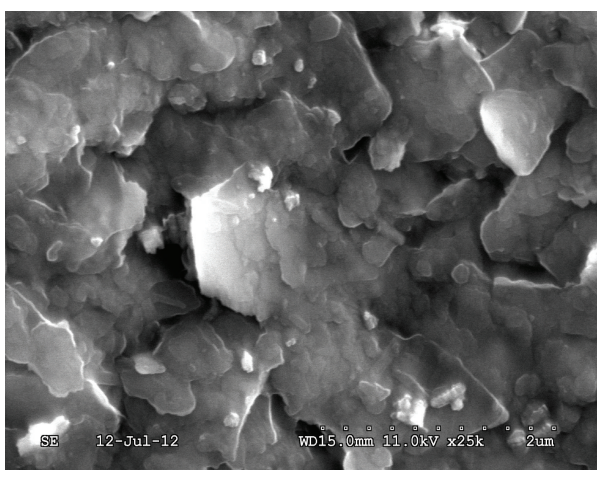

(c)

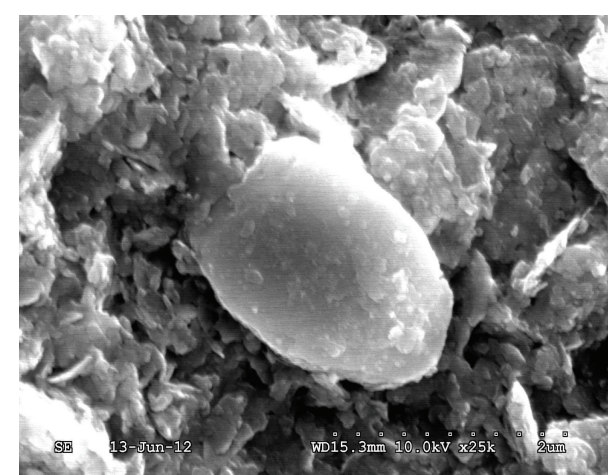

(b)

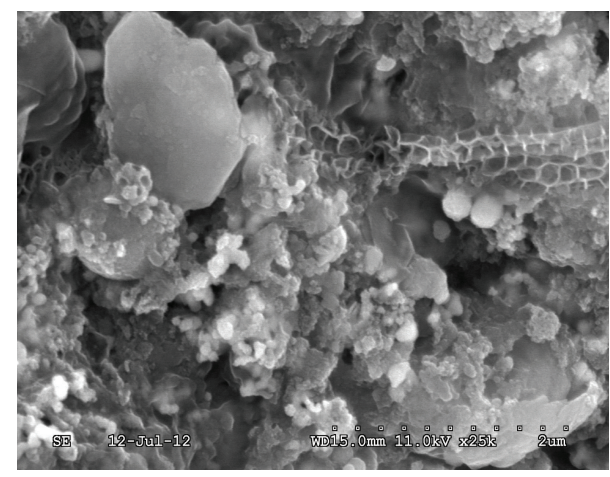

(d)

FIGURE 1: SEM images of the (a) smectitic, (b) mixed, (c) kaolinitic, and (d) biosolid macrocolloid aggregates.

compared to the macrocolloids. Higher ionic strength tends to promote flocculation rather than dispersion [38].

The nanocolloids exhibited greater cation exchange capacity than did the macrocolloids, likely due to their smaller particle size and greater surface area (Table 1). The smectitic colloids had the highest CEC amongst the mineral colloids, as expected, followed by the mixed mineralogy and the kaolinitic colloids (Table 1). The biosolid colloids exhibited the greatest CEC as compared to the mineral colloids, likely due to their higher organic carbon content. At their natural $\mathrm{pH}$ or the $\mathrm{pH}$ measured in suspension without any chemical adjustments, there were larger exchangeable $\mathrm{Ca}^{2+}$ and $\mathrm{Mg}^{2+}$ concentrations in the nanocolloids than in their corresponding macrocolloid fractions (Table 1). The presence of these divalent cations might be an additional reason why nanocolloids were less dispersible than the macrocolloids, as divalent cations such as $\mathrm{Ca}^{2+}$ promote flocculation $[14,15]$.

The nanocolloids had greater organic carbon (OC) and nitrogen content than did the macrocolloids, with OC decreasing in the following order: biosolid $>$ smectitic $>$ mixed > kaolinitic (Table 1). The impact of OC on WDC content is not straightforward; some studies show a positive correlation between OC and WDC content $[1,14,16,19,39$, 40] whereas others have reported weak correlations [36]. The fact that WDC in the nanocolloid fraction was always lower than that of the corresponding macrocolloids implies that OC might be promoting flocculation rather than dispersion.
3.3.2. Zeta Potential. Nano- and macrocolloids exhibited negative zeta potentials which became more negative with an increase in $\mathrm{pH}$ from all three soil types (Figure 4). The mineral nanocolloid zeta potentials were more negative than their corresponding macrocolloids, particularly as $\mathrm{pH}$ increased above 6 for the smectitic and mixed soil types. The kaolinitic nanocolloids showed more negative zeta potentials than the macrocolloids across the entire $\mathrm{pH}$ range (Figure 4(b)). Assuming that zeta potential measurements approximate the charge residing in the diffuse layer of the electrical double layer [41], our results indicate that all colloids bear net negative surface charge. Thus, a more negative zeta potential with increasing $\mathrm{pH}$ is ascribed to the deprotonation of edge sites on phyllosilicates, making these sites more negatively charged [42].

Despite the predominance of kaolinite in the macroand nanocolloid fractions from the kaolinitic soil type, there was never a point where the zeta potential (estimated from particle mobility) was zero (Figure 4(b)). This suggests that the isoelectric point, defined as the $\mathrm{pH}$ of zero mobility [41, $43]$, is $<4$. Pure kaolinite exhibits an isoelectric point at $\mathrm{pH}$ 4.25 [44]. The fact that an isoelectric point was not reached under our experimental conditions for kaolinitic colloids might be due to the presence of other minerals (Table 2) and organic carbon (Table 1). An isoelectric point was not reached for the smectitic colloids either, which is not surprising given the low values typically reported $(<\mathrm{pH} 2.5)$ (Figure $4(\mathrm{a})$ ). 


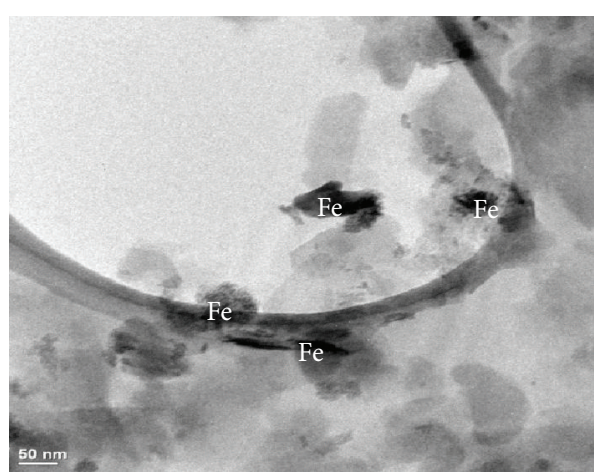

(a)

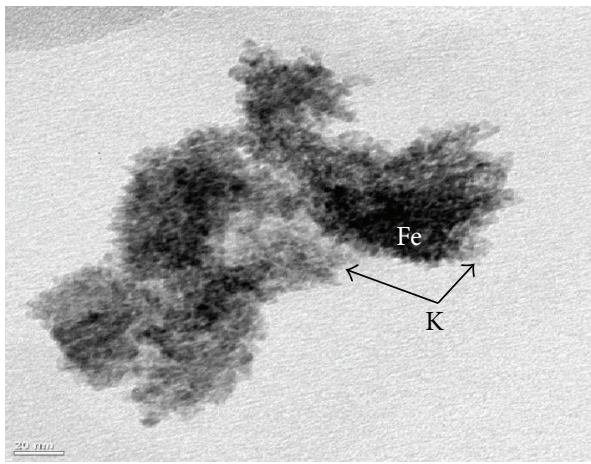

(c)

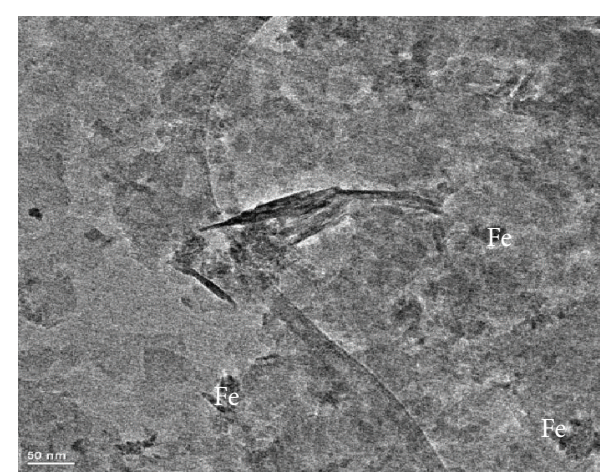

(b)

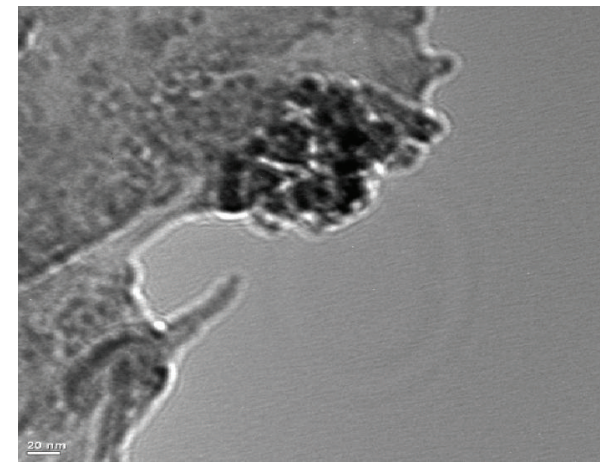

(d)

FIGURE 2: TEM images of (a) smectitic nanocolloids with interbedded iron minerals (Fe), (b) mixed mineralogy nanocolloid aggregates showing HIV/vermiculite and interbedded iron minerals (Fe), (c) an aggregate of small hexagonally shaped kaolinitic particles with interbedded iron (Fe), and (d) a biosolid nanocolloid aggregate (mineralogy as verified by morphology and XRD/TG analysis).

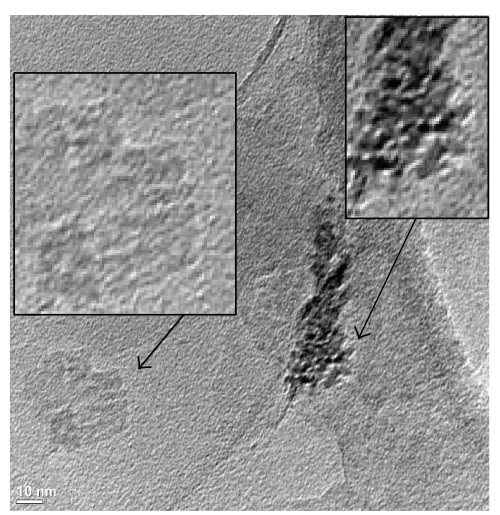

(a)

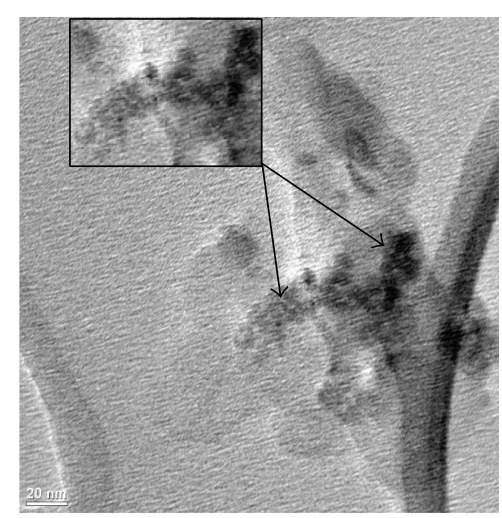

(b)

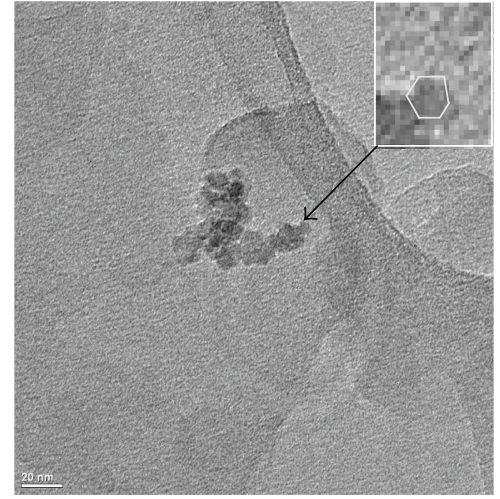

(c)

FIGURE 3: TEM images of the (a) montmorillonite nanocolloids showing some interlayering/disorder of the individual atoms, (b) mixed mineralogy nanocolloids showing some interlayering/disorder of the individual atoms, and (c) kaolinitic nanocolloids showing kaolinitic hexagonal morphology.

The increase in negative zeta potential with $\mathrm{pH}$ in all colloid types is also due to the presence of organic carbon. Organic carbon has been proposed to coat naturally occurring colloids, imparting negative surface charge and enhancing dispersion $[1,14,19,45,46]$. Where carboxyl groups are present, an increase in $\mathrm{pH}$ promotes deprotonation and would contribute to the negative zeta potentials (Figure 4).
The biosolid colloids showed different trends than the mineral colloids, with the bionanocolloids having less negative zeta potentials $(-11.60$ to $-3.30 \mathrm{mV})$ than their corresponding biomacrocolloids $(-11.7$ to $-33.0 \mathrm{mV})$ (Figure 4(d)). Additionally, the bionanocolloids became less negative with increasing $\mathrm{pH}$, while the biomacrocolloid zeta potentials became more negative with increasing $\mathrm{pH}$ 


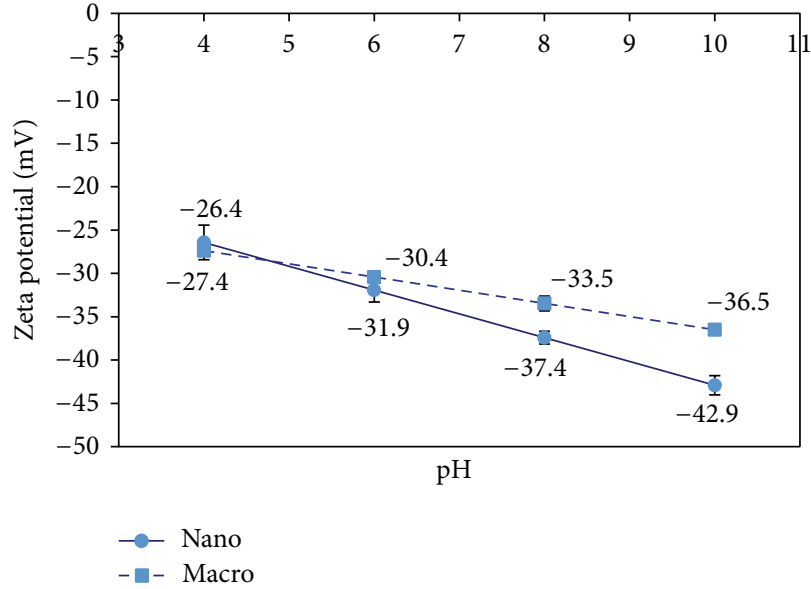

(a) Smectitic

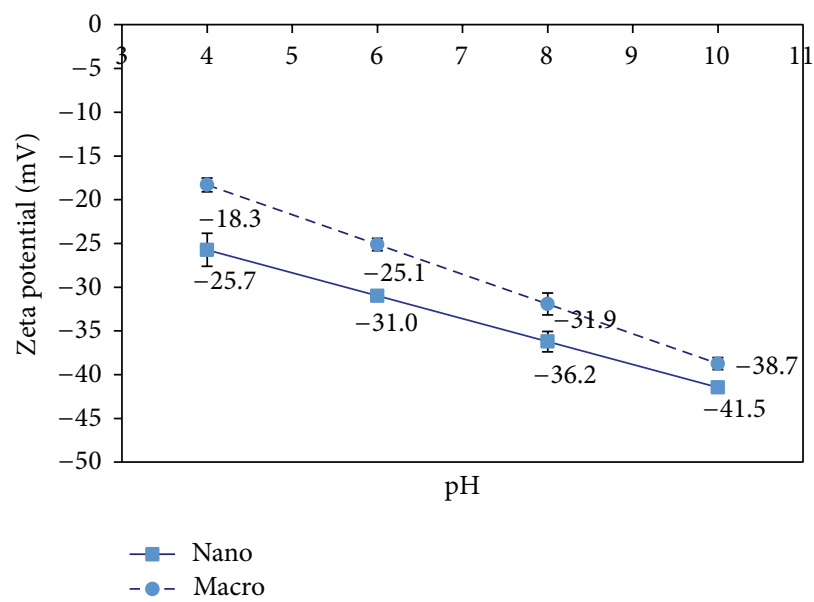

(c) Kaolinitic

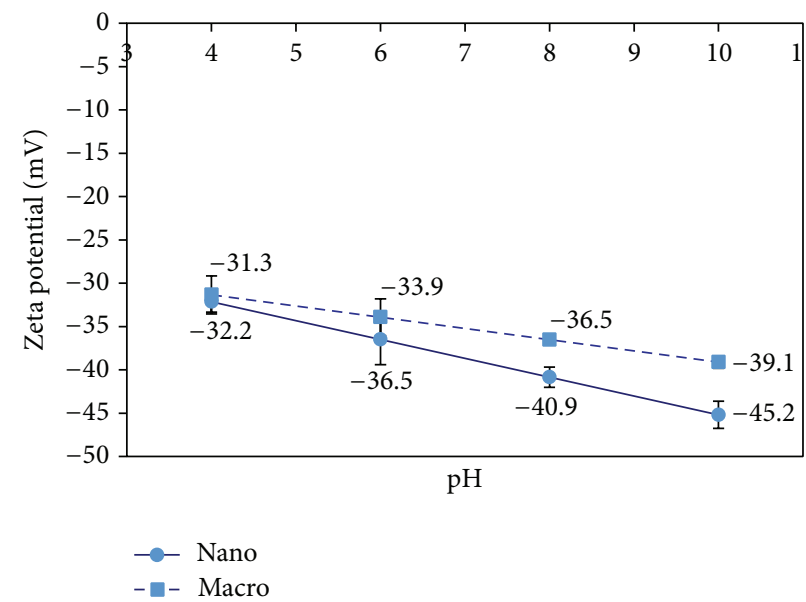

(b) Mixed

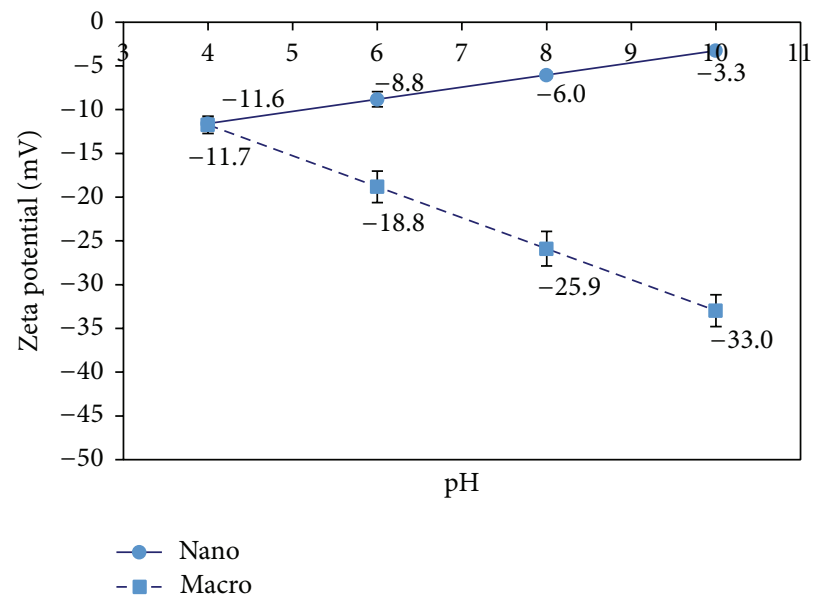

(d) Biosolid

FIGURE 4: Nano- and macrocolloid zeta potential as a function of $\mathrm{pH}$. Mean values of triplicate soil colloid samples with background electrolyte of $0.001 \mathrm{M} \mathrm{NaCl}$. Error bars represent standard deviations among triplicate measurements.

TABLE 2: Mineralogical compositions of nano- and macrocolloids.

\begin{tabular}{|c|c|c|c|c|c|c|c|c|}
\hline \multirow{3}{*}{$\begin{array}{l}\text { Properties } \\
\text { Size class }\end{array}$} & \multicolumn{8}{|c|}{ Colloids } \\
\hline & \multicolumn{2}{|c|}{ Smectitic } & \multicolumn{2}{|c|}{ Mixed } & \multicolumn{2}{|c|}{ Kaolinitic } & \multicolumn{2}{|c|}{ Biosolid } \\
\hline & Macro & Nano & Macro & Nano & Macro & Nano & Macro & Nano \\
\hline Kaolinite $(\%)^{\ddagger}$ & 29 & 30 & 42 & 46 & 52 & 55 & $\mathrm{NA}^{\S}$ & $\mathrm{NA}^{\S}$ \\
\hline Goethite $(\%)^{\ddagger}$ & 7 & 9 & 5 & 7 & 12 & 15 & $\mathrm{NA}^{\S}$ & $\mathrm{NA}^{\S}$ \\
\hline Gibbsite $(\%)^{\ddagger}$ & 0 & 0 & 0 & 0 & 5 & 6 & $\mathrm{NA}^{\S}$ & $\mathrm{NA}^{\S}$ \\
\hline Quartz $(\%)^{\ddagger}$ & 6 & 4 & 5 & 3 & 4 & 2 & $\mathrm{NA}^{\S}$ & $\mathrm{NA}^{\S}$ \\
\hline $\operatorname{Mica}(\%)^{\ddagger}$ & 10 & 6 & 31 & 30 & 3 & 3 & $\mathrm{NA}^{\S}$ & $\mathrm{NA}^{\S}$ \\
\hline Smectite $(\%)^{\ddagger}$ & 48 & 51 & 0 & 0 & 0 & 0 & $\mathrm{NA}^{\S}$ & $\mathrm{NA}^{\S}$ \\
\hline $\operatorname{MVI}^{9}(\%)^{\ddagger}$ & 0 & 0 & 7 & 7 & 0 & 0 & $\mathrm{NA}^{\S}$ & $\mathrm{NA}^{\S}$ \\
\hline $\operatorname{HIV}^{\#}(\%)^{\ddagger}$ & 0 & 0 & 10 & 7 & 24 & 19 & $\mathrm{NA}^{\S}$ & $\mathrm{NA}^{\S}$ \\
\hline
\end{tabular}

${ }^{\ddagger}$ Mineral percentage as determined using X-Ray diffraction and thermogravimetric data (Karathanasis, 2008 [31]).

${ }^{\S} \mathrm{NA}$ : not applicable.

MVI: mica-vermiculite interstratified.

${ }^{\#}$ HIV: hydroxy-interlayered vermiculite. 
(Figure 4(d)). Organic surface functional groups that may be dominating the biomacrocolloid zeta potentials are likely carboxyl groups, which offer negative surface charge (depending on the full structural formation) above pH's 2.5 and 6 [43]. Overall, the biosolid colloids exhibited more positive zeta potentials than the mineral colloids which might be due to their greater ionic strength (Table 1).

\subsection{Mineralogical Characteristics}

3.4.1. XRD and TG. XRD analysis of the smectitic nano- and macrocolloids indicated montmorillonite to be the dominant mineral (>50\%), with 001 peaks at $1.4 \mathrm{~nm}$ under Mg treatments, expansion to $1.6 \mathrm{~nm}$ under Mg-glycerolated conditions, and a collapse to $1.0 \mathrm{~nm}$ with $\mathrm{K}$-heat treatments (Table 2). The kaolinitic nano- and macrocolloids contained $>50 \%$ kaolinite with 001 peaks at $0.7 \mathrm{~nm}$ under $\mathrm{Mg}$ treatments, no expansion with $\mathrm{Mg}$-glycerolation, and a disappearance of the $0.7 \mathrm{~nm}$ peak under K-heat treatments of $550^{\circ} \mathrm{C}$ (Table 2). The mixed mineralogy nano- and macrocolloids contained kaolinite, hydroxyl-interlayered vermiculite (HIV), and mica as the most abundant minerals. The presence of HIV was indicated through the resistance of collapse of the $1.4 \mathrm{~nm}$ peak during K-heat treatments $\left(100^{\circ} \mathrm{C}\right.$ heat treatment showed collapse to $1.3 \mathrm{~nm}, 350^{\circ} \mathrm{C}$ heat treatment showed collapse to $1.2 \mathrm{~nm}$, and $550^{\circ} \mathrm{C}$ heat treatment showed partial collapse to $1.1 \mathrm{~nm}$ with a partial peak resisting collapse at $1.2 \mathrm{~nm}$ ). The presence of mica was indicated in all samples by peaks at $1.0 \mathrm{~nm}$ under all treatment conditions (Table 2). TG analysis confirmed XRD compositions and showed slight increases of kaolinite, goethite, and gibbsite in the nanocolloid fractions as compared to the macrocolloids (Table 2). Multiple studies have shown mineral fractions with diameters less than $200 \mathrm{~nm}$ to be enriched in kaolinite, gibbsite, and Fe oxides and to exhibit decreases in mica and hydroxyl-interlayered vermiculite than their corresponding larger clay size fractions $[12,13,16,17]$.

Surprisingly, the combined XRD and TG quantitative analysis showed only slight mineralogical differences between the nano- and macrocolloid fractions, including noted decreases in quartz content and increases in some phyllosilicate minerals and goethite within the nanocolloid fractions (Table 2). The lack of expected drastic differences may be due to adhesion of nanoparticles to macrocolloid surfaces, as evidenced in the SEM images (Figure 1), rendering mineralogical differences inscrutable. However, more significant differences were observed in elemental percentages of individual particles obtained from the EDS data. Generally, nanocolloids had on average $9.25 \%$ more $\mathrm{Si}$ than $\mathrm{Al}$ and $9 \%$ more Fe than $\mathrm{Si}(\mathrm{LSD}=4.92, \mathrm{CV}=1.96$, and $\alpha=0.05)$. The macrocolloids had an average of 17\% more Si than $\mathrm{Al}$ and $19 \%$ less Fe than $\mathrm{Si}(\mathrm{LSD}=2.74, \mathrm{CV}=1.96$, and $\alpha=0.05$ as calculated using Fisher's protected LSD). These trends, in addition to increased kaolinite and goethite within the nanocolloid fractions (Table 2), insinuate that the nanocolloids have a decreased ratio of $\mathrm{Si}: \mathrm{Al}$ and an increase in $\mathrm{Fe}$ as compared to the macrocolloids, which demonstrates a higher degree of weathering and greater goethite content. The SEM and TEM images alsoindicated an increase in iron minerals with decreased size as well as a more prominent platy morphology in the nanocolloid fractions (Figures 1 and 2). Additionally, the XRD patterns displayed a discernible loss of crystallinity in the nanocolloids as compared to their corresponding macrocolloids, suggesting a higher presence of amorphous and poorly-crystalline materials which may greatly affect both stability and surface reactivity of the colloids (Figure 5).

3.4.2. IR Characterization. The DRIFT spectra of the mineral nano- and macrocolloids (Figures 6-8) indicated the presence of $\mathrm{O}-\mathrm{H}$ stretching vibrations between 3700 and $3000 \mathrm{~cm}^{-1}$ and $\mathrm{O}-\mathrm{H}$ bending vibrations from 950 to $650 \mathrm{~cm}^{-1}$ due to the presence of structural $\mathrm{O}-\mathrm{H}$ in minerals [32]. Peaks located between 900 and $1200 \mathrm{~cm}^{-1}$ correspond to $\mathrm{Si}-\mathrm{O}$ stretching. A broad peak centered at 1404 to $1425 \mathrm{~cm}^{-1}$ is attributed to the presence of carboxyl groups, while broad peaks at $1634 \mathrm{~cm}^{-1}$ are likely a combination of three features: $\mathrm{C}=\mathrm{O}$ stretching of amide functional groups (referring to amide I), aromatic $\mathrm{C}=\mathrm{C}$ stretching, and asymmetric $\mathrm{COO}^{-}$ stretching [47] (Figures 6-8). Additionally, the appearance of a shoulder at $1720 \mathrm{~cm}^{-1}$ occurred in each mineral spectra, which is assigned to the $\mathrm{C}=\mathrm{O}$ stretch of $\mathrm{COOH}$ groups (Figures 6-8).

DRIFT data from the smectitic nano- and macrocolloids (Figure 6) complimented the XRD findings and confirmed a small amount of kaolinite $\left(3697 \mathrm{~cm}^{-1}\right)$ in both size fractions. The nanocolloid DRIFT pattern also indicated greater amounts of quartz (through stronger intensities at 697, 780, and $800 \mathrm{~cm}^{-1}$ ) and biotite mica (stronger intensities at 1000 and $750 \mathrm{~cm}^{-1}$, Figure 6) than the macrocolloid pattern [32$34,48,49]$. The mixed nano- and macrocolloid DRIFT patterns (Figure 7) indicated kaolinite $(3696,3620,1008$, and $914 \mathrm{~cm}^{-1}$ ) and HIV and vermiculite (combination of 3550 with broad $3400-3200 \mathrm{~cm}^{-1}$ peaks), with a noted decrease in the breadth of expression in the nanocolloid pattern for the HIV and vermiculite peaks.

In the kaolinitic nano- and macrocolloids, the presence of kaolinite was confirmed by the $\mathrm{O}-\mathrm{H}$ stretching peaks located at $3696,3668,3650$, and $3620 \mathrm{~cm}^{-1}$, while the bands at 3527,3449 , and $3395 \mathrm{~cm}^{-1}$ are assigned to gibbsite (Figure 8). In both the nano- and macrocolloids, the peaks at 939 and $914 \mathrm{~cm}^{-1}$ correspond to $\mathrm{O}-\mathrm{H}$ bending vibrations of kaolinite. The broad band around $3200-3400 \mathrm{~cm}^{-1}$ in the kaolinitic macrocolloids (Figure 8) also corresponds to an $\mathrm{O}-\mathrm{H}$ stretching vibration due to phenolic $\mathrm{O}-\mathrm{H}$, confirmed by the shoulder at $1266 \mathrm{~cm}^{-1}$ which is the diagnostic $\mathrm{C}-\mathrm{OH}$ stretch of phenolics [47], whereas the nanocolloid pattern has the $\mathrm{O}-\mathrm{H}$ stretching region merged into one broad band centered at roughly $3395 \mathrm{~cm}^{-1}$ with appearances of kaolinite peaks as small shoulders at 3696 and $3650 \mathrm{~cm}^{-1}$ (Figure 8). In addition, there was appearance of a sharp peak at $1384 \mathrm{~cm}^{-1}$ in the nanocolloid pattern, which is assigned to either surface carboxyl-Fe groups $\left(1380 \mathrm{~cm}^{-1}\right)$ or nitrate.

Within all nanocolloid soil types, the DRIFT spectra revealed the presence of a shoulder near $1540 \mathrm{~cm}^{-1}$ (Figures $6-8)$, which is assigned to the amide II peak $[47,50]$. This feature was not present in the macrocolloids. The presence 


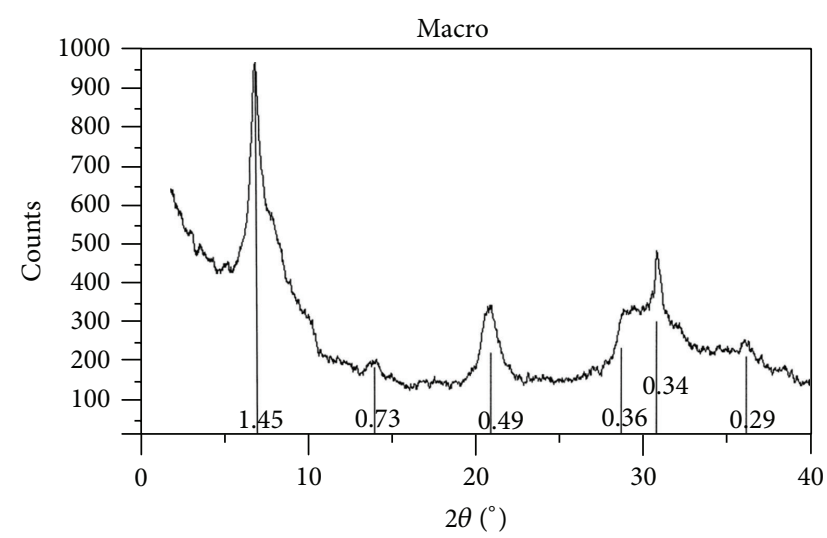

(a)

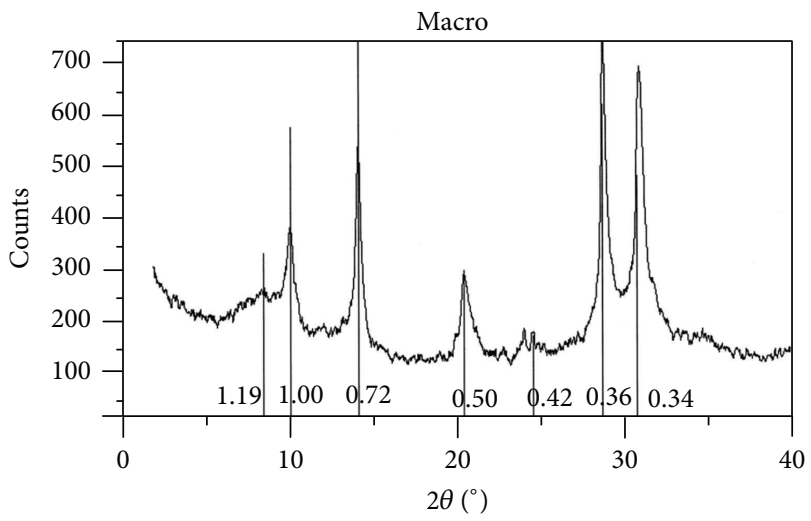

(c)

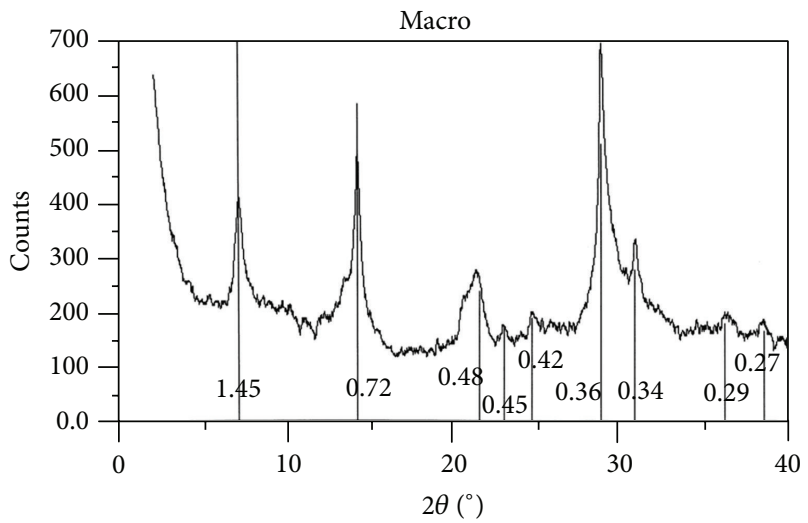

(e)

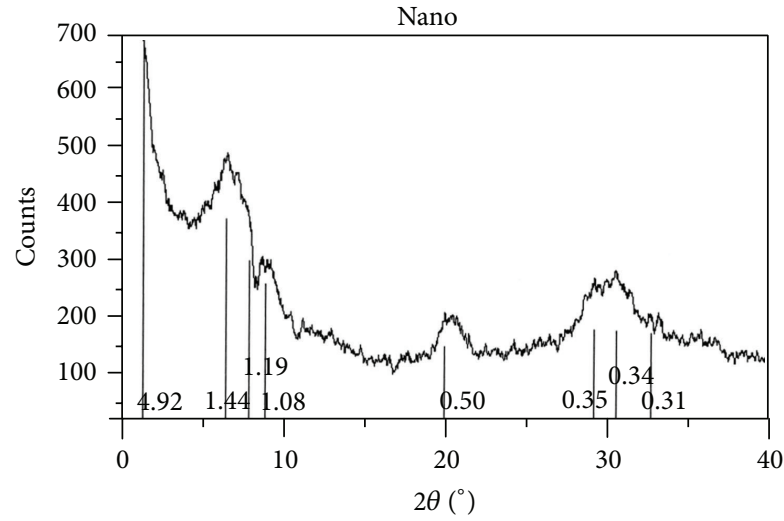

(b)

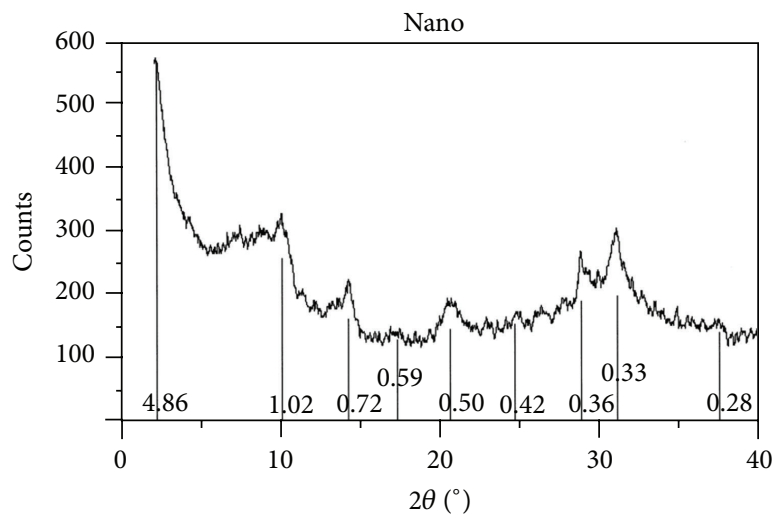

(d)

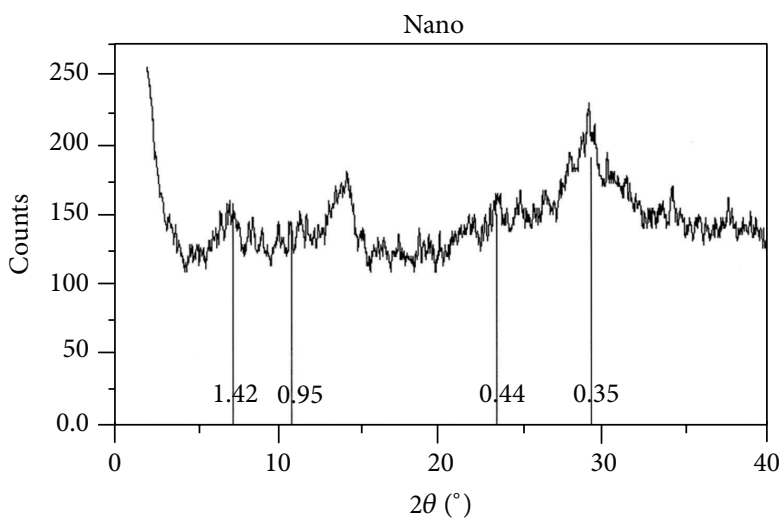

(f)

FIGURE 5: Mg-saturated XRD patterns of the (a) smectitic macro- and (b) nanocolloids, (c) mixed macro- and (d) nanocolloids, and the (e) kaolinitic macro- and (f) nanocolloids.

of amide functional groups in the nanocolloids agrees with Calabi-Floody et al. [51], who noted amide groups in nanoclays and not in coarser clay fractions. This is especially significant in the fact that all three soil samples were removed from B horizons.

Within the biosolid colloids (Figure 9) there were signatures of phenol groups (broad peaks at 1250 and between 3600 and $3000 \mathrm{~cm}^{-1}$, aliphatic C-H groups $\left(2950 \mathrm{~cm}^{-1}\right)$, and other methyl groups $\left(2950,2410\right.$, and $\left.2420 \mathrm{~cm}^{-1}\right)$, as well as carboxyl groups $\left(1700,1660\right.$, and $\left.\left.1400 \mathrm{~cm}^{-1}\right)\right)$ in both the nano- and macrocolloid fractions [52]. Both size fractions had shoulder peaks representing amide II bonds at $1550 \mathrm{~cm}^{-1}$, with prominent nitrate peaks at $1384 \mathrm{~cm}^{-1}$, while the $\mathrm{C}-\mathrm{O}$ stretch of polysaccharides wasrepresented by peaks between 950 and $1170 \mathrm{~cm}^{-1}$ (Figure 9) [32-34, 48, 49, 52, 53]. The bionanocolloid pattern indicated a greater prevalence of carboxyl, phenolic, amide, and methyl groups than did the biomacrocolloids through greater absorption values (Figure 9). Additionally, the bionanocolloids had peaks at 2398, 2232, and $1843 \mathrm{~cm}^{-1}$, indicating a greater presence of aromatic 


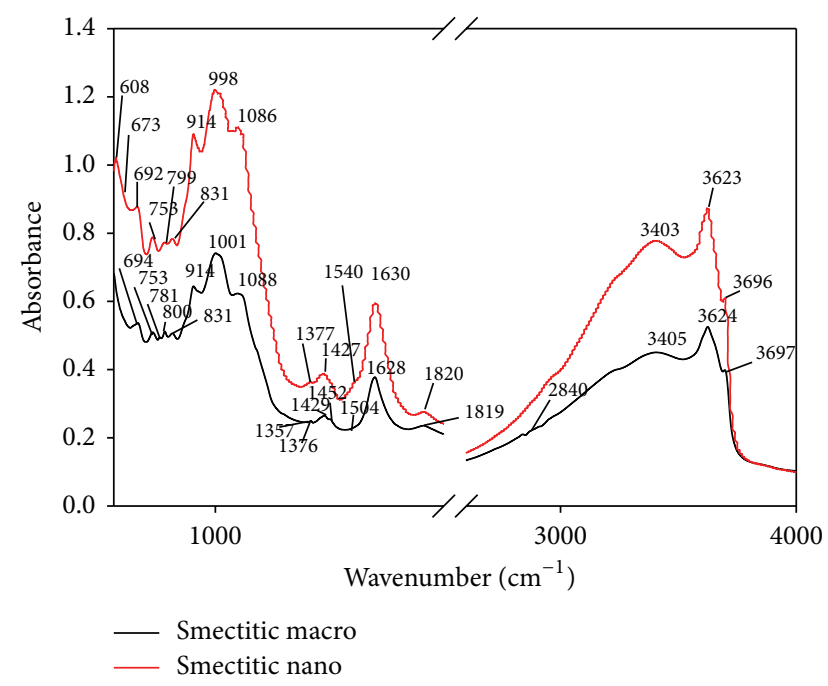

FIGURE 6: Smectitic nano- and macrocolloid FTIR characterization.

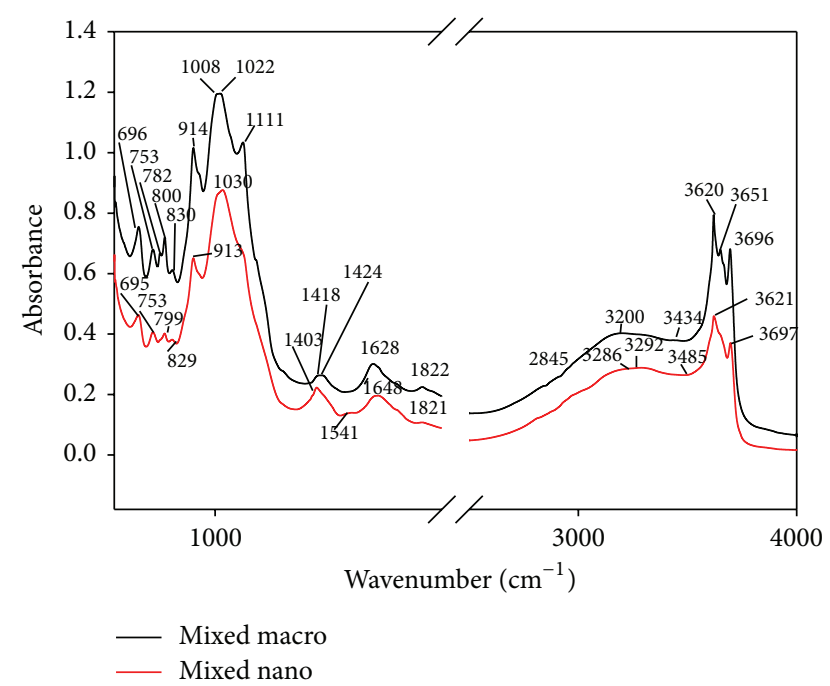

FIGURE 7: Mixed mineralogy nano- and macrocolloid FTIR characterization.

$\mathrm{C}=\mathrm{C}$ bonds than the biomacrocolloids (Figure 9) [52]. The bionanocolloid pattern also indicated a greater presence of $\mathrm{CO}_{2} \mathrm{H}$ groups through the shift and occurrence of a greater intensity shoulder peak at $1767 \mathrm{~cm}^{-1}$, whereas the biomacrocolloid pattern showed a smaller shoulder peak at $1732 \mathrm{~cm}^{-1}$ (Figure 9) [52]. The extensive organic functional groups characterized in the biocolloids DRIFT spectra provide ample surface area for reactivity with contaminants as indicated by the larger surface area measured within the biocolloids over that of the mineral colloids (Table 1).

\section{Conclusions}

Nanocolloids fractionated by centrifugation appeared to have a larger average size range $(>100 \mathrm{~nm})$ than typical nanoparticles due to irregular shape and/or limited aggregation. Nanoparticles were also found to be attached to the

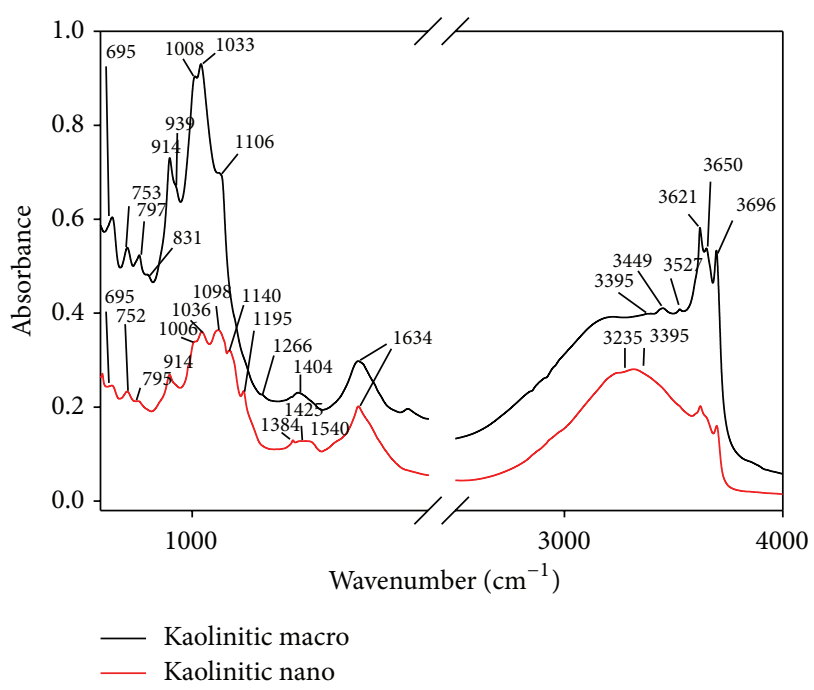

FIGURE 8: Kaolinitic nano- and macrocolloid FTIR characterization.

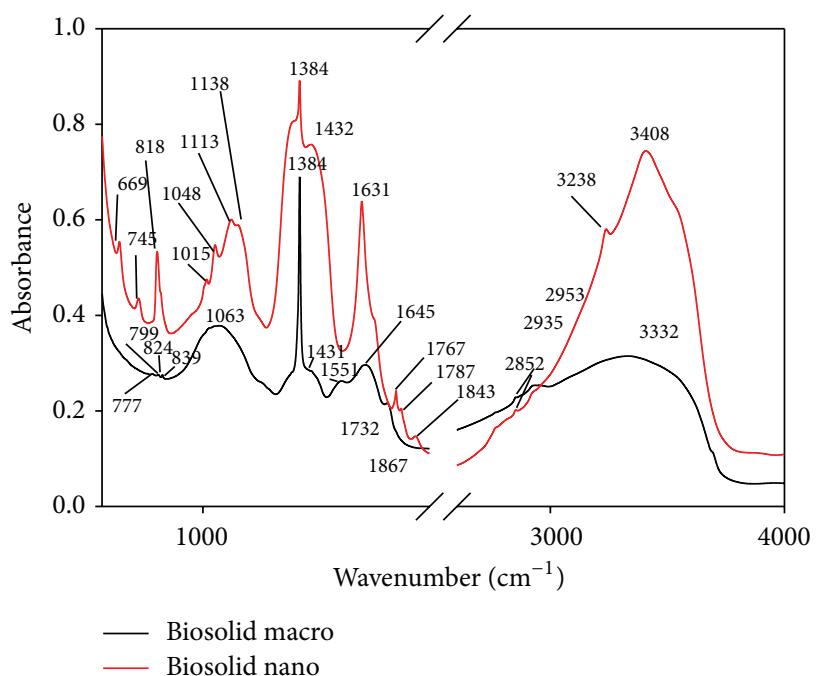

FIGURE 9: Biosolid nano- and macrocolloid FTIR characterization.

surfaces of some macrocolloid fractions, suggesting macronano aggregate behavior. The occurrences of nanoparticle clusters within the nanocolloids and of macro-nano aggregates in the macrocolloids may have modified somewhat the behavior of the different sized fractions, obscuring some of the expected differences between the two size classes. Nevertheless, nanocolloids exhibited greater surface reactivity, as evidenced by higher negatively charged surfaces and larger surface areas. The higher negatively charged surfaces and sodium adsorption ratios of the nanocolloids over their corresponding macrocolloids also indicated greater potential for colloidal stability. In contrast, the biosolid nanocolloids showed less stability than corresponding macrocolloids due to shifts towards a more positive surface charge with $\mathrm{pH}$ changes. The presence of siloxane, aluminol, and carboxylic surface functional groups on the nano- and macrocolloids may provide surface sites that can interact and potentially sorb contaminants depending on the conditions in the 
subsurface environment. Mineralogical differences between the nano- and macrocolloids may have been obscured by the attachment of nanoparticles to macrocolloid surfaces, but generally the nanocolloids displayed poor crystallinity in comparison to their corresponding macrocolloids, which may further enhance their surface reactivity and sorption potential. Further. TEM images indicated morphological shape changes with decreased size, which may alter nanocolloid surface free energy, reactivity, and surface area availability for contaminant sorption. Overall, this study showed that nanocolloids-due to their physicochemical and morphological differences from corresponding macrocolloids-may have the potential for greater chemical reactivity, sorption, and transport of contaminants than macrocolloids. This has important ramifications in water pollution and remediation processes. However, due to their heterogeneous nature, predictions of their physicochemical behavior in natural environments and associated risks based exclusively on size separations may be different from what it was originally anticipated.

\section{Conflict of Interests}

The authors declare that there is no conflict of interests regarding the publication of this paper.

\section{References}

[1] P. Christian, F. Von Der Kammer, M. Baalousha, and T. Hofmann, "Nanoparticles: structure, properties, preparation and behaviour in environmental media," Ecotoxicology, vol. 17, no. 5, pp. 326-343, 2008.

[2] A. D. Karathanasis, "Composition and transport behavior of soil nanocolloids in natural porous media," in Nanoparticles in the Water Cycle, F. H. Frimmel and R. NieBner, Eds., chapter 4, Springer, Berlin, Germany, 2010.

[3] J. F. McCarthy and J. M. Zachara, "Subsurface transport of contaminants. Mobile colloids in the subsurface environment may alter the transport of contaminants," Environmental Science and Technology, vol. 23, no. 5, pp. 496-502, 1989.

[4] A. D. McNaught and W. A. Blackwell, Eds., IUPAC Compendium of Chemical Terminology, IUPAC, Science, 2nd edition, 1997.

[5] M. F. Hochella Jr., S. K. Lower, P. A. Maurice et al., "Nanominerals, mineral nanoparticles, and earth systems," Science, vol. 319, no. 5870, pp. 1631-1635, 2008.

[6] P. A. Maurice and M. F. Hochella, "Chapter 5 nanoscale particles and processes. A new dimension in soil science," Advances in Agronomy, vol. 100, pp. 123-153, 2009.

[7] B. K. G. Theng and G. Yuan, "Nanoparticles in the soil environment," Elements, vol. 4, no. 6, pp. 395-399, 2008.

[8] M. F. Hochella Jr., "Nanogeoscience: from origin to cutting-edge applications," Elements, vol. 4, no. 6, pp. 373-379, 2008.

[9] G. A. Waychunas and H. Zhang, "Structure, chemistry, and properties of mineral nanoparticles," Elements, vol. 4, no. 6, pp. 381387, 2008.

[10] T. M. Tsao, Y. M. Chen, and M. K. Wang, "Origin, separation and identification of environmental nanoparticles: a review," Journal of Environmental Monitoring, vol. 13, no. 5, pp. 11561163, 2011.
[11] K. C. Haering and G. K. Evanylo, "Mid-atlantic nutrient management handbook. CSREES mid-atlantic regional water quality program," 2006, MAWQP \#06-02, http://www.mawaterquality.org/capacity_building/ma_nutrient_mgmt_handbook.html.

[12] J. P. Bryant and J. B. Dixon, "Clay mineralogy and weathering of red-yellow podzolic soil from quartz mica schist in the Alabama Piedmont," Clays and Clay Minerals, vol. 12, pp. 509-521, 1963.

[13] J. B. Dixon, "Quantitative analysis of kaolinite and gibbsite in soils by differential thermal and selective dissolution methods," Clays and Clay Minerals, vol. 14, pp. 83-90, 1966.

[14] C. Kjaergaard, H. C. B. Hansen, C. B. Koch, and K. G. Villholth, "Properties of water-dispersible colloids from macropore deposits and bulk horizons of an agrudalf," Soil Science Society of America Journal, vol. 68, no. 6, pp. 1844-1852, 2004.

[15] C. Kjaergaard, P. Moldrup, L. W. de Jonge, and O. H. Jacobsen, "Colloid mobilization and transport in undisturbed soil columns. II. The role of colloid dispersibility and preferential flow," Vadose Zone Journal, vol. 3, no. 2, pp. 424-433, 2004.

[16] D. I. Kaplan, P. M. Bertsch, and D. C. Adriano, "Mineralogical and physicochemical differences between mobile and nonmobile colloidal phases in reconstructed pedons," Soil Science Society of America Journal, vol. 61, no. 2, pp. 641-649, 1997.

[17] R. Kretzschmar, W. P. Robarge, and S. B. Weed, "Flocculation of kaolinitic soil clays: effects of humic substances and iron oxides," Soil Science Society of America Journal, vol. 57, no. 5, pp. 1277-1283, 1993.

[18] S. Yun-Hwei, "Sorption of humic acid to soil: the role of soil mineral composition," Chemosphere, vol. 38, no. 11, pp. 24892499, 1999.

[19] D. I. Kaplan, P. M. Bertsch, D. C. Adriano, and W. P. Miller, "Soilborne mobile colloids as influenced by water flow and organic carbon," Environmental Science and Technology, vol. 27, no. 6, pp. 1193-1200, 1993.

[20] Y. Ouyang, D. Shinde, R. S. Mansell, and W. Harris, "Colloidenhanced transport of chemicals in subsurface environments: a review," Critical Reviews in Environmental Science and Technology, vol. 26, no. 2, pp. 189-204, 1996.

[21] R. Kretzschmar, M. Borkovec, D. Grolimund, and M. Elimelech, "Mobile subsurface colloids and their role in contaminant transport," Advances in Agronomy, vol. 66, pp. 121-193, 1999.

[22] J. F. McCarthy and L. D. McKay, "Colloid transport in the subsurface: past, present, and future challenges," Vadose Zone Journal, vol. 3, no. 2, pp. 326-337, 2004.

[23] A. D. Karathanasis, D. M. C. Johnson, and C. J. Matocha, "Biosolid colloid-mediated transport of copper, zinc, and lead in waste-amended soils," Journal of Environmental Quality, vol. 34, no. 4, pp. 1153-1164, 2005.

[24] T. Németh, J. Jiménez-Millán, P. Sipos, I. Abad, R. JiménezEspinosa, and Z. Szalai, "Effect of pedogenic clay minerals on the sorption of copper in a Luvisol B horizon," Geoderma, vol. 160, no. 3-4, pp. 509-516, 2011.

[25] R. Zhu and S. Lu, "A high-resolution TEM investigation of nanoparticles in soils," in Molecular Environmental Soil Science at the Interfaces in the Earth's Critical Zone, pp. 282-284, Springer, Berlin, Germany, 2010.

[26] Y. Deng, N. White, and J. B. Dixon, "Soil mineralogy laboratory manual Texas A\&M," 2009.

[27] J. I. Goldstein, D. E. Newbury, P. Echlin, D. C. Joy, C. Fiori, and E. Lifshin, Scanning Electron Microscopy and X-Ray Microanalysis, Plenum Press, New York, NY, USA, 2nd edition, 1992. 
[28] D. L. Carter, M. D. Heilman, and C. L. Gonzalez, "Ethylene glycol monoethylene ether for determining surface area of silicate minerals," Soil Science Society of America Journal, vol. 100, pp. 356-360, 1965.

[29] R. A. Griffin and J. J. Jurinak, "Estimation of activity coefficients from the electrical conductivity of natural aquatic systems and soil extracts," Soil Science, vol. 116, no. 1, pp. 26-30, 1973.

[30] NRCS, "Soil survey laboratory methods manual," Soil Survey Investment Report 42, USDA, National Soil Survey Center, Lincoln, Neb, USA, 1996.

[31] A. D. Karathanasis, "Thermal analysis of soil minerals," in Methods of Soil Analysis, Part 5-Mineralogical Methods, A. L. Ulery and L. R. Drees, Eds., chapter 5, pp. 117-160, Soil Science Society of America Book 5, Madison, Wis, USA, 2008.

[32] V. C. Farmer, "Vibrational spectroscopy in mineral chemistry," in The Infrared Spectra of Minerals, V. C. Farmer, Ed., Mineralogical Society Monograph 4, London, UK, 1974.

[33] J. Madejova, "FTIR techniques in clay mineral studies," Vibrational Spectroscopy, vol. 31, pp. 1-10, 2003.

[34] J. L. White, "Interpretation of infrared spectra of soil minerals," Soil Science, vol. 112, pp. 22-31, 1971.

[35] D. L. Carter, M. M. Mortland, and W. D. Kemper, Methods of Soil Analysis-Part 1. Physical and Mineralogical Methdos, Agronomy monograph no. 9, chapter 16, American Society of Agronomy, Soil Science Society of America, 1986.

[36] A. K. Seta and A. D. Karathanasis, "Water dispersible colloids and factors influencing their dispersibility from soil aggregates," Geoderma, vol. 74, no. 3-4, pp. 255-266, 1996.

[37] A. K. Seta and A. D. Karathanasis, "Atrazine adsorption by soil colloids and co-transport through subsurface environments," Soil Science Society of America Journal, vol. 61, no. 2, pp. 612617, 1997.

[38] D. Hesterberg and A. L. Page, "Flocculation series test yielding time-invariant critical coagulation concentrations of sodium illite," Soil Science Society of America Journal, vol. 54, no. 3, pp. 729-735, 1990.

[39] M. Hassellöv and F. von der Kammer, "Iron oxides as geochemical nanovectors for metal transport in soil-river systems," Elements, vol. 4, no. 6, pp. 401-406, 2008.

[40] S. Ottofuelling, F. Von Der Kammer, and T. Hofmann, "Commercial titanium dioxide nanoparticles in both natural and synthetic water: comprehensive multidimensional testing and prediction of aggregation behavior," Environmental Science and Technology, vol. 45, no. 23, pp. 10045-10052, 2011.

[41] G. Sposito, The Surface Chemistry of Soils, Oxford University Press, Oxford, UK, 1984.

[42] E. Frey and G. Lagaly, "Selective coagulation in mixed colloidal suspensions," Journal of Colloid and Interface Science, vol. 70, no. 1, pp. 46-55, 1979.

[43] M. E. Essington, Soil and Water Chemistry: An Integrative Approach, CRC Press LLC, Boca Raton, Fla, USA, 2004.

[44] S. A. Carroll-Webb and J. V. Walther, "A surface complex reaction model for the $\mathrm{pH}$-dependence of corundum and kaolinite dissolution rates," Geochimica et Cosmochimica Acta, vol. 52, no. 11, pp. 2609-2623, 1988.

[45] P. M. Bertsch and J. C. Seaman, "Characterization of complex mineral assemblages: implications for contaminant transport and environmental remediation," Proceedings of the National Academy of Sciences of the United States of America, vol. 96, no. 7, pp. 3350-3357, 1999.
[46] J. Chorover and G. Sposito, "Colloid chemistry of kaolinitic tropical soils," Soil Science Society of America Journal, vol. 59, no. 6, pp. 1558-1564, 1995.

[47] A. U. Baes and P. R. Bloom, "Diffuse reflectance and transmission Fourier transform infrared (DRIFT) spectroscopy of humic and fulvic acids," Soil Science Society of America Journal, vol. 53, no. 3, pp. 695-700, 1989.

[48] N. Dupuy and F. Douay, "Infrared and chemometrics study of the interaction between heavy metals and organic matter in soils," Spectrochimica Acta A: Molecular and Biomolecular Spectroscopy, vol. 57, no. 5, pp. 1037-1047, 2001.

[49] P. A. Shroeder, "Infrared spectroscopy in clay science," in Teaching Clay Science, A. Rule and S. Guggenheim, Eds., vol. 11 of CMS Workshop Lectures, pp. 181-206, The Clay Mineral Society, Aurora, Colo, USA, 2002.

[50] M. V. Cheshire, C. Dumat, A. R. Fraser, S. Hillier, and S. Staunton, "The interaction between soil organic matter and soil clay minerals by selective removal and controlled addition of organic matter," European Journal of Soil Science, vol. 51, no. 3, pp. 497-509, 2000.

[51] M. Calabi-Floody, J. S. Bendall, A. A. Jara et al., "Nanoclays from an Andisol: extraction, properties and carbon stabilization," Geoderma, vol. 161, no. 3-4, pp. 159-167, 2011.

[52] B. Chefetz, P. G. Hatcher, Y. Hadar, and Y. Chen, "Chemical and biological characterization of organic matter during composting of municipal solid waste," Journal of Environmental Quality, vol. 25, no. 4, pp. 776-785, 1996.

[53] J. Niemeyer, Y. Chen, and J.-M. Bollag, "Characterization of humic acids, composts, and peat by diffuse reflectance Fouriertransform infrared spectroscopy," Soil Science Society of America Journal, vol. 56, no. 1, pp. 135-140, 1992. 

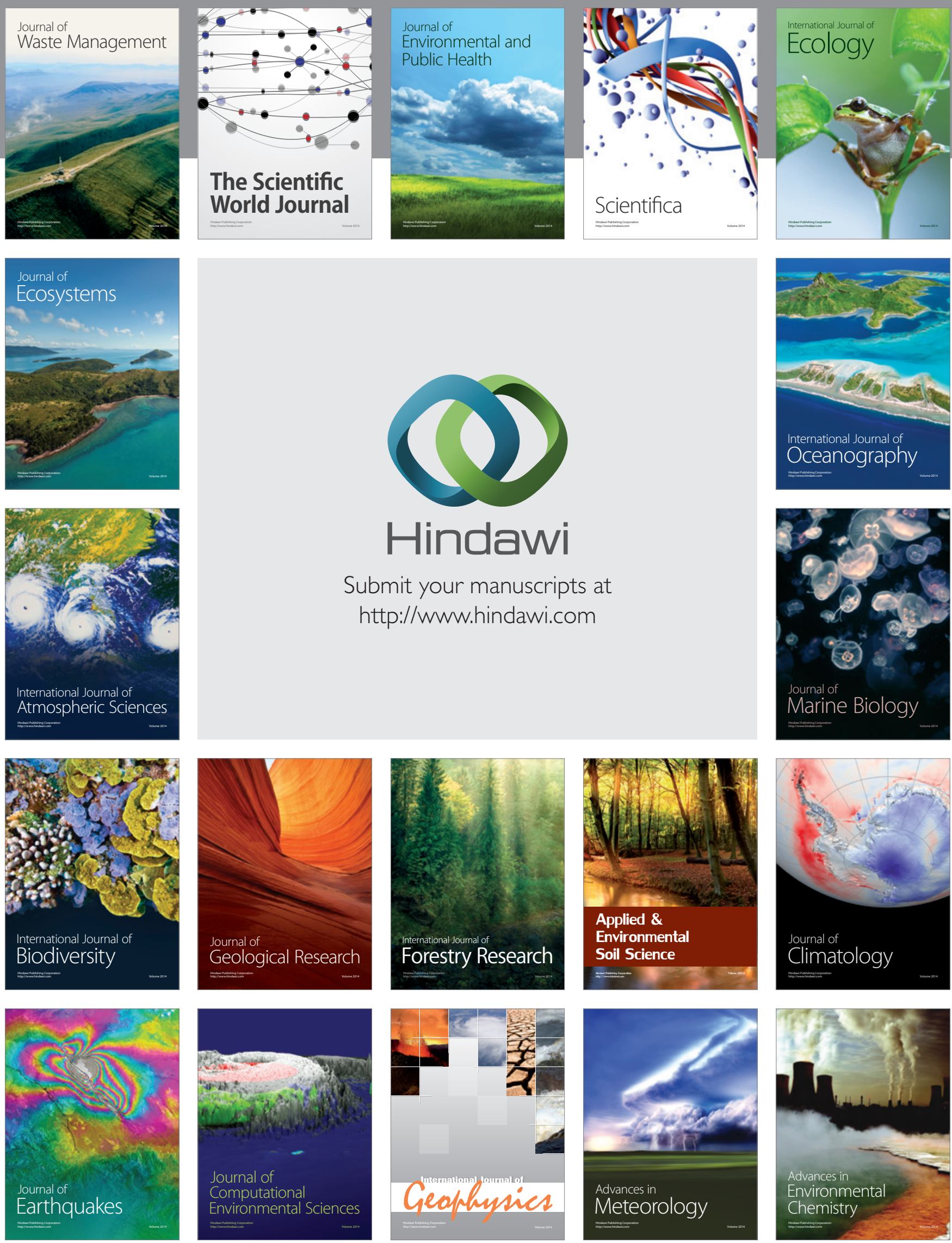